Jurnal Indonesia Sosial Teknologi: p-ISSN: 2723 - 6609

e-ISSN : 2745-5254

Vol. 2, No. 1 Januari 2021

\title{
ANALISA PENGASUTAN MOTOR 4.16 KV SEBAGAI AIR PENGISI BOILER DI PLTU GRESIK
}

\author{
Rival Abder Rasul, Denny Irawan dan Rini Puji Astutik \\ Jurusan Teknik Elektro Universitas Muhammadiyah Gresik \\ Email: rival_170603@umg.ac.id, astutik_rpa@umg.com,den2mas@umgl.com
}

\begin{abstract}
The starting current when the induction motor is running can reach 5 - 7 times the nominal current. A large current will produce a large amount of heat, this heat can damage the motor itself, so an appropriate starting method is needed to reduce the starting current in the motor. Large currents can cause voltage dips on the bus and other loads. Starting in a 3 phase induction motor has several methods, namely Direct On Line (DOL), star-delta, auto transformer and soft starter. To be able to know the motor starting current can be simulated using ETAP Power Station software. From the simulation results performed using ETAP, the following results are obtained, for the direct on line (DOL) method of starting, the starting current is 2807.9 A or 5.25 times the nominal current and the voltage dip on the bus is $14.88 \%$. For the star-delta method, the starting current is 1039.2 A or 2.12 times the nominal current and the voltage dip on the bus is $5.51 \%$. For the auto transformer method, the starting current is 790.2 A or 1.61 times the nominal current and the voltage dip is $4.19 \%$. And for the soft starter method, the starting current is $1708 \mathrm{~A}$ or 3.5 times the nominal current and the voltage dip is $9.08 \%$.
\end{abstract}

Keyword : ETAP; direct on line (DOL); star-delta; auto trafo; soft starter; voltage dip

\begin{abstract}
Abstrak
Arus awal pada saat motor induksi dijalankan dapat mencapai $5-7$ kali arus nominal. Arus yang besar akan menghasilkan panas yang besar pula, panas ini dapat merusak motor itu sendiri dan tujuan penelitian ini agar dapat mencari metode pengasutan yang tepat untuk mengurangi arus start yang besar pada motor. Pengasutan pada motor induksi 3 fasa mempunyai beberapa metode yaitu Direct On Line (DOL), star-delta, auto trafo dan soft starter. Untuk dapat mengetahui arus start motor dapat menggunakan metode simulasi dengan software ETAP Power Station. Dari hasil simulasi yang dilakukan menggunakan ETAP didapatkan hasil sebagai berikut, untuk metode pengasutan direct on line (DOL) diperoleh arus start sebesar 2807,9 A atau 5,25 kali arus nominal dan voltage dip pada bus sebesar $14,88 \%$. Untuk metode star-delta diperoleh arus start 1039,2 A atau 2,12 kali arus nominal dan voltage dip pada bus sebesar 5,51\%. Untuk metode auto trafo diperoleh arus start sebesar 790,2 A atau 1,61 kali arus nominal dan voltage dip sebesar 4,19\%. Dan untuk metode soft starter diperoleh arus start sebesar $1708 \mathrm{~A}$ atau 3,5 kali arus nominal dan voltage dip sebesar 9,08\%.
\end{abstract}


Kata kunci: ETAP; direct on line (DOL); star-delta; auto trafo; soft starter; voltage dip

\section{Pendahuluan}

Di jaman modern seperti sekarang ini listrik sebagai sumber energi yang sangat penting dan telah menjadi kebutuhan utama untuk memenuhi segala kebutuhan energi di masyarakat. Sehingga kebutuhan akan listrik saat ini maupun dimasa yang akan datang akan terus meningkat. Untuk memenuhi kebutuhan energi listrik yang terus meningkat maka sistem dari pembangkitan listrik harus mempunyai peralatan yang handal dan dapat meminimalisir terjadinya kerusakan. Karena seringkali pada pembangkit listrik terjadi kerusakan pada isolasi winding motor dengan berbagai macam penyebab (Fransdita \& Harnoko, 2010).

Salah satu peralatan penunjang produksi listrik yaitu boiler feed pump. Boiler feed pump digunakan untuk menyalurkan air pengisi di dalam boiler. Boiler feed pump menggunakan motor induksi 3 fasa dengan tegangan $4000 \mathrm{~V}$ dan daya $2960 \mathrm{~kW}$ dan menggunakan metode pengasutan DOL (Direct On Line) dengan tegangan sebesar itu harus memperhatikan arus awal pada saat motor dijalankan. Pengasutan tegangan penuh saat dilakukan dengan beban tinggi menyebabkan motor akan menarik arus yang sangat besar, dimana akan menyebabkan voltage dip pada beban - beban yang lain (Husodo \& Irsyad, 2017). Arus yang besar dapat merusak motor itu sendiri dengan jadwal pengoperasian yang berulang - ulang sehingga diperlukan pengoperasian yang tepat. Selama ini metode pengasutan yang dipakai dapat menyebabkan kerusakan karena panas yang berlebih pada motor yang didapat salah satunya dari arus pengasutan yang besar (Nur Falah \& Prasetya, 2017).

Dalam jurnal ini akan membandingkan beberapa metode pengasutan pada motor boiler feed pump yang bermanfaat untuk mendapatkan metode yang dapat meningkatkan efisiensi pemakaian energy listrik (Pawawoi, 2009). Metode pengasutan yang digunakan yaitu sistem DOL (Direct On Line), star delta, auto trafo dan soft starter. Pengujian akan dilakukan dengan metode simulasi dengan menggunakan software ETAP Power Station.

\section{Metode Penelitian}

Metode yang digunakan yaitu dengan simulasi menggunakan software ETAP (Riyadi H, Warsito, \& Facta, 2011). Pada ETAP kita memasukkan parameter parameter sesuai dengan spesifikasi motor boiler feed pump seperti yang ditunjukkan pada tabel 1. Sebelum melakukan simulasi harus membuat single line diagram untuk analisa sistem pengasutan pada penelitian ini, simulasi yang dilakukan yaitu metode star delta, auto trafo dan soft starter. Metode peneltian ini merupakan tahapan-tahapan penelitian untuk mencapai tujuan penelitian. Berikut ini diagram alir metode penelitian seperti ditunjukkan pada gambar 2 .

Tabel 1. Spesifikasi motor

\begin{tabular}{lll}
\hline \multicolumn{1}{c}{ Besaran } & Nilai & \multicolumn{1}{c}{ Satuan } \\
\hline Daya & 2960 & $\mathrm{~kW}$ \\
Tegangan & 4000 & $\mathrm{~V}$ \\
Kecepatan & 1480 & $\mathrm{RPM}$ \\
Faktor Daya & 0,91 &
\end{tabular}

Jurnal Indonesia Sosial Teknologi, Vol. 2, No. 1, Januari 2021 
Rival Abder Rasul, Denny Irawan dan Rini Puji Astutik

\begin{tabular}{lll} 
Frekuensi & 50 & $\mathrm{~Hz}$ \\
Arus Pengasutan & 2192 & $\mathrm{~A}$ \\
$\begin{array}{l}\text { Arus Beban } \\
\text { Penuh }\end{array}$ & 488 & $\mathrm{~A}$ \\
\hline
\end{tabular}

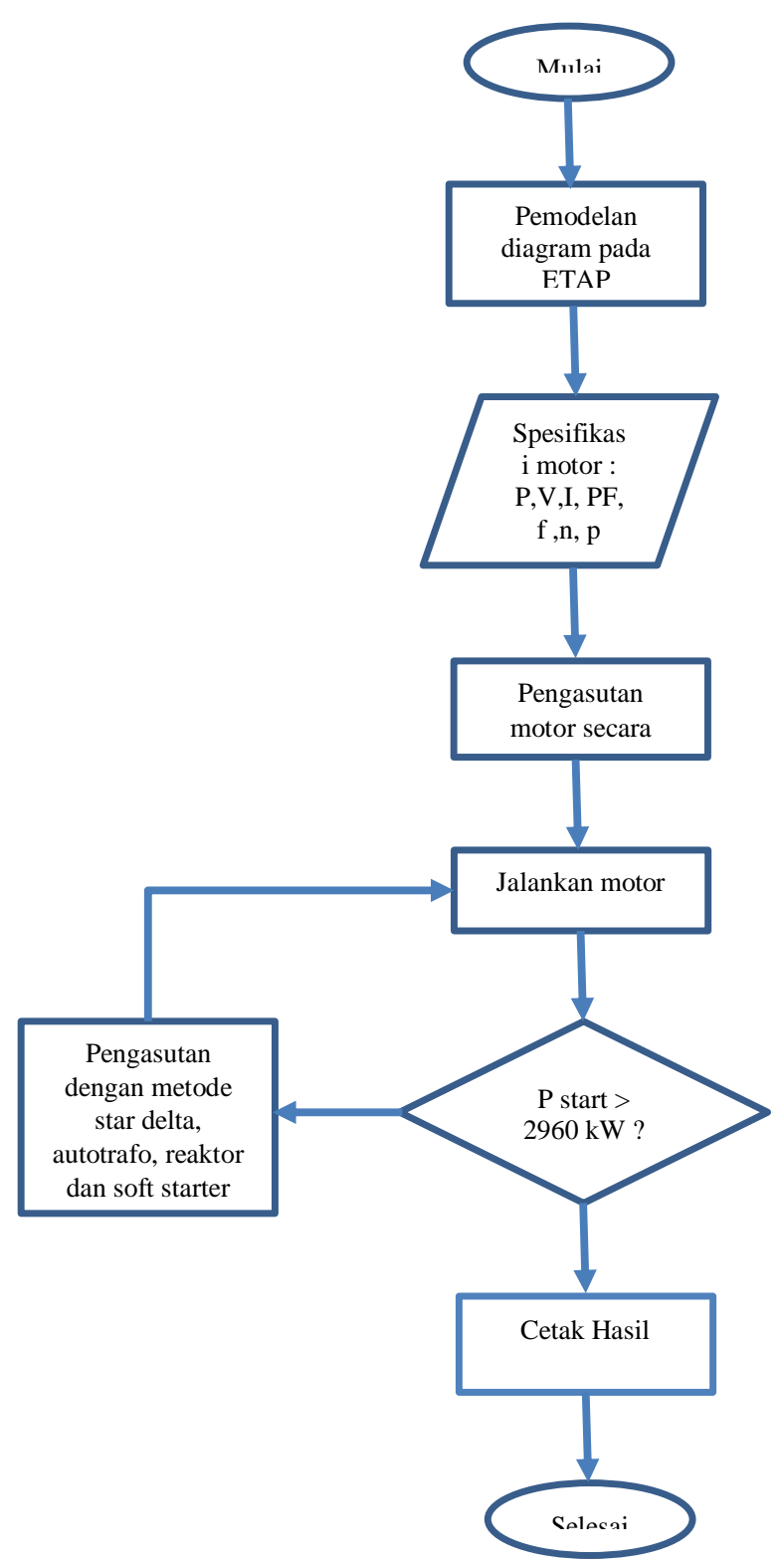

Gambar 2. Diagram alir simulasi start motor

Berdasarkan gambar 2 ditunjukkan bahwa tahapan-tahapan pada metode penelitian meliputi simulasi star delta, auto trafo, reaktor dan soft starter. Simulasi dilakukan untuk mengetahui pengasutan motor pada saat dioperasikan. Dari simulasi 
akan diketahui nilai dari pengasutan dengan beberapa metode tersebut dan dapat diketahui metode mana yang memiliki efisiensi yang lebih bagus.

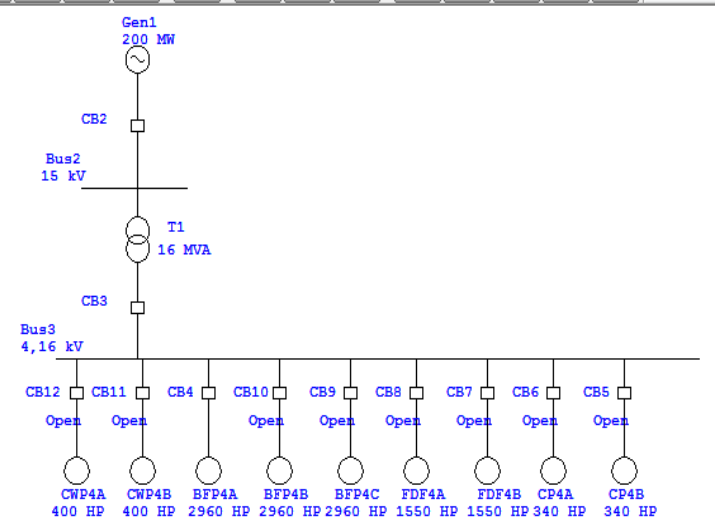

Gambar 3. Single line diagram

\section{Hasil dan Pembahasan}

\section{Pengujian Sistem Direct On-Line (DOL)}

Pada pengujian ini, didapatkan hasil arus starting sebesar 2807,9 A atau setara dengan 5,75 kali arus nominal dengan waktu starting 1,2 detik kemudian arus turun pada kondisi normal menjadi 475,1 A seperti pada gambar 4. Dan pada saat motor start terjadi voltage dip pada bus $4,16 \mathrm{kv}$ menjadi $3,541 \mathrm{kv}$ atau turun sebesar $14,88 \%$ yang dilihat pada gambar 5 .

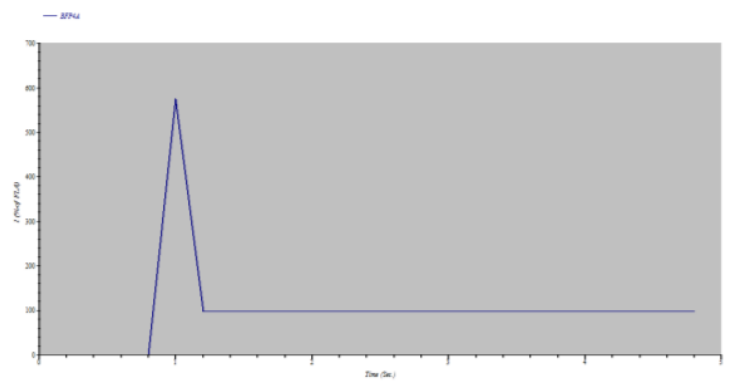

Gambar 4. Kenaikan arus start dengan metode DOL

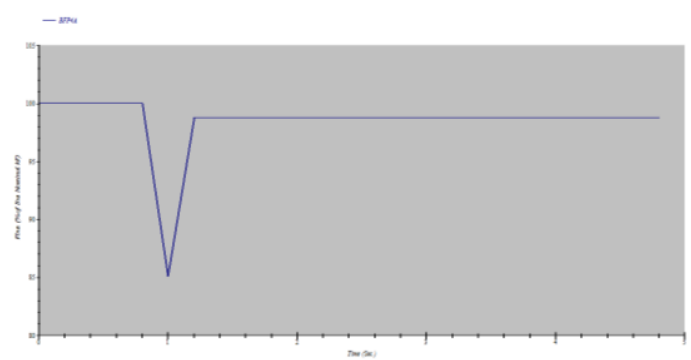

Gambar 5. Voltage dip saat start motor

\section{Pengujian Sistem Star Delta}

Dengan metode starting star-delta menggunakan pengaturan waktu 2 detik untuk perubahan dari star ke delta. Didapatkan arus start sebesar 1039,2 A atau 2,12 kali dari 
Rival Abder Rasul, Denny Irawan dan Rini Puji Astutik

arus nominal dan setelah 2 detik berubah ke delta dan terjadi lonjakan arus dengan arus start mencapai 2807,9 A atau 5,75 kali dari arus nominal (Sugiharto B, Warsito, \& Facta, 2011). Dengan voltage dip pada bus turun menjadi $94,49 \%$ atau turun $5,51 \%$. Pada tabel 2 dapat dilihat perubahan kenaikan arus start dengan metode star-delta, serta penurunan tegangan atau voltage dip pada bus $4,16 \mathrm{kv}$.

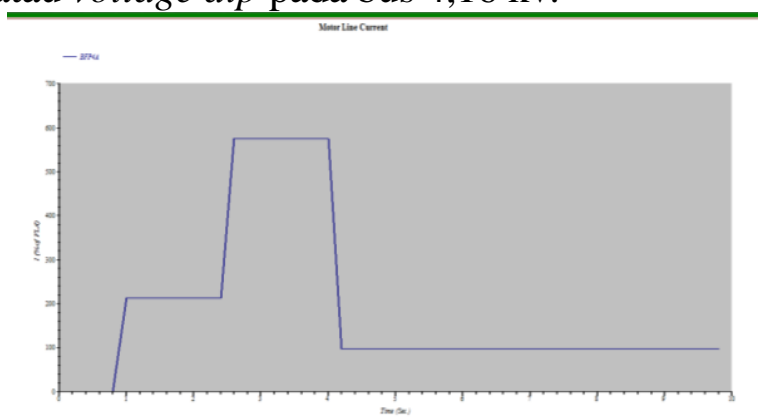

Gambar 6. Kenaikan arus start dengan metode star-delta

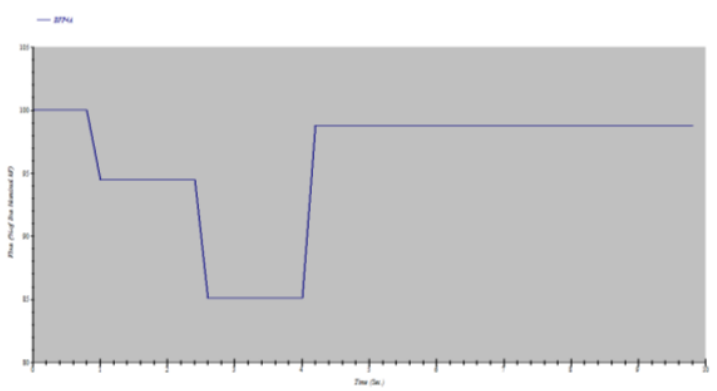

Gambar 7. Voltage dip saat start dengan metode star-delta

Tabel 2. Perubahan arus start dan voltage dip star-delta

\begin{tabular}{l|l|l}
$\begin{array}{c}\text { Time } \\
(\mathrm{s})\end{array}$ & $\begin{array}{c}\text { Current } \\
(\% \text { FLA })\end{array}$ & $\begin{array}{c}\text { \% Bus } \\
\text { voltage }\end{array}$ \\
\hline 1 & $212,96 \%$ & $94,49 \%$ \\
\hline 1,4 & $212,96 \%$ & $94,49 \%$ \\
\hline 2,2 & $212,96 \%$ & $94,49 \%$ \\
\hline 2,6 & $575,39 \%$ & $85,12 \%$ \\
\hline 3,4 & $575,39 \%$ & $85,12 \%$ \\
\hline 4,2 & $97,35 \%$ & $98,77 \%$
\end{tabular}

\section{Pengujian Sistem Auto Trafo}

Pengujian dengan menggunakan metode auto trafo tegangan terminal motor diturunkan menjadi 50\% - 95\% dari tegangan penuh trafo dengan tujuan untuk membuat arus pengasutan kecil. Setelah kecepatan motor induksi stabil, transformator tegangan diputuskan. Pada pengujian kali ini tap yang digunakan adalah sebesar 50\% dengan waktu selama 2 detik (Wahyudy, 2016).

Didapatkan arus start dengan metode auto trafo sebesar 790,2 A atau 1,61 kali arus nominal motor serta voltage dip pada bus menjadi 3,986 kv atau turun sebesar 4,19\% dan setelah 2 detik arus awal mengalami kenaikan sebesar 2571,5 A atau 5,26 
kali arus nominal selama 0,2 detik. Seperti dapat dilihat pada tabel 3 perubahan kenaikan arus serta penurunan tegangan pada bus $4,16 \mathrm{kv}$ atau voltage dip (Permana, Yuningtyastuti, \& Sukmadi, 2016).

Tabel 3. Perubahan arus start dan voltage dip auto trafo

\begin{tabular}{l|l|l}
$\begin{array}{c}\text { Time } \\
(\mathrm{s})\end{array}$ & $\begin{array}{c}\text { Current } \\
(\% \text { FLA })\end{array}$ & $\begin{array}{c}\text { \% Bus } \\
\text { voltage }\end{array}$ \\
\hline 1,0 & $161,92 \%$ & $95,81 \%$ \\
\hline 1,4 & $221,82 \%$ & $94,26 \%$ \\
\hline 2,2 & $263,16 \%$ & $90,61 \%$ \\
\hline 2,6 & $442,72 \%$ & $88,55 \%$ \\
\hline 3,0 & $526,94 \%$ & $86,37 \%$ \\
\hline 4,2 & $97,35 \%$ & $98,77 \%$
\end{tabular}

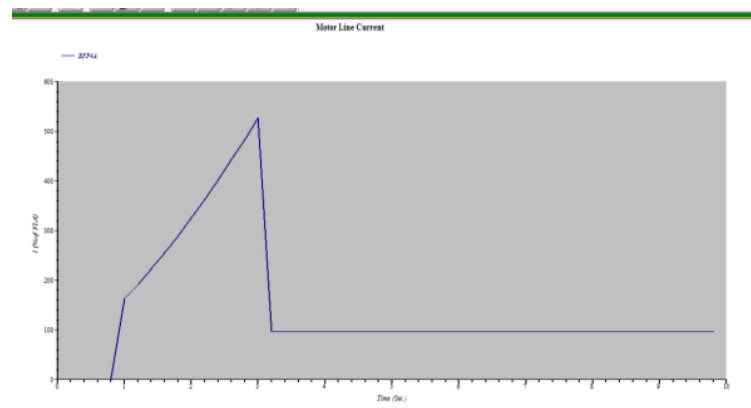

Gambar 8. Perubahan arus start dengan metode auto trafo

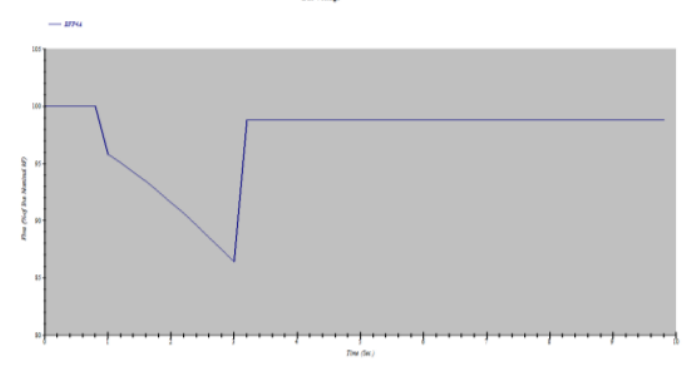

Gambar 9. Voltage dip metode auto trafo

\section{Pengujian Sistem Soft Starter}

Pada pengujian soft starter ini menggunakan metode current control pada $350 \%$ arus asutnya. Setelah pengujian didapat arus sebesar 1708 A yang sama dengan $350 \%$ arus asutnya (Roza, 2018). Dan tegangan pada bus turun atau voltage dip sebesar 9,08\%. Pada tabel 4 dapat dilihat perubahan arus start dari detik 1 sampai detik ke 3,4 atau sampai motor sesuai dengan arus nominalnya.

Tabel 4. Perubahan arus start dan voltage dip soft starter

\begin{tabular}{ccc}
$\begin{array}{c}\text { Time } \\
(\mathrm{s})\end{array}$ & $\begin{array}{r}\text { Current } \\
(\% \text { FLA })\end{array}$ & $\begin{array}{c}\text { \% Bus } \\
\text { voltage }\end{array}$ \\
\hline 1,0 & $350 \%$ & $90,92 \%$ \\
\hline 1,4 & $350 \%$ & $90,92 \%$
\end{tabular}

Jurnal Indonesia Sosial Teknologi, Vol. 2, No. 1, Januari 2021 
Rival Abder Rasul, Denny Irawan dan Rini Puji Astutik

\begin{tabular}{lll}
2,2 & $256 \%$ & $93,37 \%$ \\
\hline 2,6 & $208 \%$ & $94,61 \%$ \\
\hline 3,0 & $160 \%$ & $95,86 \%$ \\
\hline 3,4 & $97,35 \%$ & $98,77 \%$
\end{tabular}

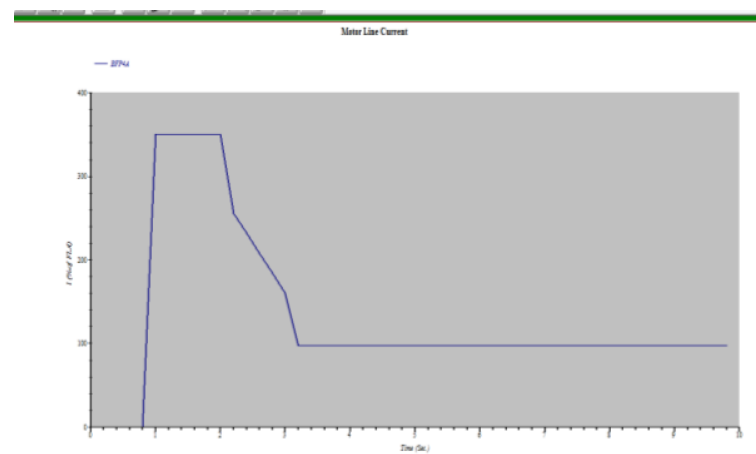

Gambar 10. Perubahan arus start dengan metode soft starter

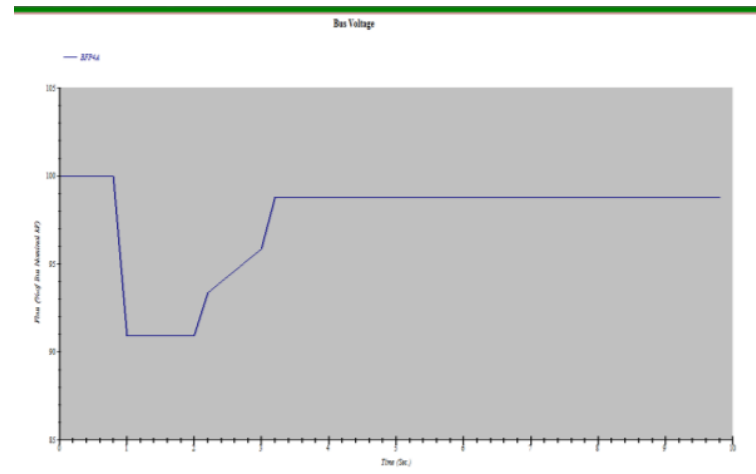

Gambar 11. Voltage dip metode soft starter

\section{Kesimpulan}

Berdasarkan hasil dari simulasi beberapa metode pengasutan menggunakan aplikasi ETAP maka dapat disimpulkan pengasutan dengan metode DOL didapatkan arus start sebesar 2807,9 A atau 5,25 kali arus nominal dan terjadi voltage dip sebesar 15\%. Pengasutan dengan metode star-delta didapatkan arus start sebesar 1039,2 A atau 2,12 kali dari arus nominal dan voltage dip sebesar 6\%. Pengasutan dengan metode auto trafo tap 50\% didapatkan arus start sebesar 790,2 A atau 1,61 kali arus nominal dan voltage dip sebesar 4,19\%. Pengasutan dengan metode soft starter didapatkan arus start sebesar 1708 A atau 3,5 kali dari arus nominal dan voltage dip sebesar 9,08\%.

Dengan cara pengoperasian motor yang di jalankan berkali - kali maka dengan pengasutan metode auto trafo merupakan metode yang paling kecil arus start nya serta voltage dip yang paling kecil juga. Pengasutan yang besar akan menghasilkan panas yang besar pula sehingga dapat berpengaruh pada sistem isolasi motor tersebut. 


\section{Bibliography}

Fransdita, Bona, \& Harnoko, Sarjiya. (2010). Analisis Jatuh Tegangan Saat Pengasutan Motor di PT. Kaltim Prima Coal. JURNAL PENELITIAN TEKNIK ELEKTRO, $3(2010)$.

Husodo, Budi Yanto, \& Irsyad, Habibul. (2017). Analisa Pengasutan Motor Induksi 3 Fasa $2500 \mathrm{Kw}$ sebagai Penggerak Fan pada Bag Filter. Sinergi, 21(3), 173-178.

Nur Falah, Ahmad Sahas, \& Prasetya, Arik. (2017). Pengaruh Knowledge Management Terhadap Kinerja Karyawan Dan Kinerja Perusahaan (Studi pada Karyawan PT Semen Indonesia Persero Tbk). Jurnal Administrasi Bisnis, 50(4), 192-198.

Pawawoi, Andi. (2009). Analisis Kedip Tegangan (Voltage Sags) Akibat Pengasutan Motor Induksi Dengan Berbagai Metode Pengasutan Studi kasus di PT. Abaisiat Raya. Jurnal Teknika, Universitas Andalas, 1(32).

Permana, Anang, Yuningtyastuti, Yuningtyastuti, \& Sukmadi, Tejo. (2016). ANALISIS PENGARUH METODE PENGASUTAN MOTOR INDUKSI 3 FASA TERHADAP KEDIP TEGANGAN YANG TERJADI PADA JARINGAN KELISTRIKAN PLTGU BLOK I PT. INDONESIA POWER UP SEMARANG MENGGUNAKAN SIMULASI SOFTWARE ETAP 12.6. 0. Transient: Jurnal Ilmiah Teknik Elektro, 5(2), 134-141.

Riyadi H, Dwi, Warsito, Agung, \& Facta, Mochammad. (2011). Soft starting pada motor induksi 3 fasa. Jurusan Teknik Elektro Fakultas Teknik Undip.

Roza, Indra. (2018). ANALISIS ARUS START MOTOR 3 PHASA PADA BOILER FEED WATER PUMP (BFWP) UNIT 1 PLTU LABUHAN ANGIN DALAM APLIKASI ETAP. SEMNASTEK UISU 2018.

Sugiharto B, Agung, Warsito, Agung, \& Facta, Mochammad. (2011). Soft Starting dan Dynamic Braking Pada Motor Induksi Tiga Fasa Menggunakan Mikrokontroler AT89S51. Jurusan Teknik Elektro Fakultas Teknik Undip.

Wahyudy, Firman Rachmat. (2016). Analisa Arus Starting Transformator Pada Pengoperasian Container Crane Di Pelabuhan. Institut Teknologi Sepuluh Nopember.

Dwiky febian. (2016)," Analisis metode starting motor induksi star delta dan soft starter pada air compressor", Analisis metode, Fakultas teknik Universitas Indonesia.

Basuki sugiharto, Agung. (2005)," Soft starting dan dynamic braking pada motor induksi 3 fasa menggunakan mikrokontroler AT89S51", Skripsi S-1, Universitas Diponegoro, Semarang. 
Rival Abder Rasul, Denny Irawan dan Rini Puji Astutik

Saadat H. (1999)," Power sistem analisis", International edition EPRI, New York: McGrw-Hill.

Modul pelatihan ETAP, (2015)," Training ETAP basic (load flow analysis) for industrial electricity system", Program studi teknik elektro, Institut Teknologi Sepuluh Nopember, Surabaya. 